\title{
RESENHA: ARTE E IMANÊNCIA: UM BOM ENCONTRO ENTRE ESPINOSA E VERMEER
}

- No original, inventio. A tradução dos termos latinos invenire e inventio particularmente complicada nos textos baconianos, tanto por sua polissemia quanto pela importância que assumem (o Novo órganon é uma logica inveniendi, há o constante louvor das inventiones, etc.). Na língua clássica, o verbo invenire possuía o sentido prioritário de "encontrar", e foi dessa forma que inventio passou a designar na retórica a arte de encontrar lugares comuns para a formulação de argumentos. No latim tardio, contudo, o mesmo verbo já possuía também o sentido de "descobrir" e às vezes mesmo de "inventar", como no seu correlato português. Assim, há uma primeira distinção a fazer, a qual é claramente formulada por Bacon: "A inventio dos argumentos não é propriamente uma inventio. Com efeito, invenire é encontrar algo desconhecido, não retomar ou lembrar algo já conhecido" (De augmentis scientiarum, $\mathrm{V}, 2$ ). Haverá, porém, uma segunda distinção: aquela entre invenire algo já existente antes mesmo da inventio (por ex., India occidentales... nobis inventa) e invenire algo que só passa a existir com a inventio (por ex., inventio operum, inventio scientiarum). Enfim, optamos por verter invenire, inventio por "descobrir", "descoberta”. Estes termos portugueses nos parecem, por um lado, afastar o sentido retórico descartado por Bacon; por outro, são tão ambíguos quanto os originais latinos: descobre-se um continente já existente bem como se descobre uma técnica até então inexistente.

2. Esclarecedora nota de Paolo Rossi: "Depois da tentativa de ataque às costas britânicas efetuada pela frota espanhola em 1588, que resultara num desastre para Felipe II, a iniciativa passara às forças inglesas, que em 1595 haviam atacado e saqueado o porto de Cádiz. O grande império espanhol, sob a aparência de uma extraordinária potência, trazia já em si os germes da dissolução: a própria amplitude dos seus domínios acaba por exaurir toda energia produtiva; o usufruto das colônias, realizado com base numa política ávida e atrasada, é para a Espanha fonte de decadência: eis o sentido da expressão baconiana."

3. No original, ad mentium areas purgandas. Literalmente: limpar as superfícies, as arenas das mentes.

4. No original, Ipse vero alieno periculo ista molior. Esta frase, devido à sua concisão, presta-se a várias interpretações; seguimos a sugestão de Paolo Rossi, que em particular lê periculum no sentido de "experimento".

\section{Marcos Ferreira de Paula*}

Resumo: Resenha do livro Espinosa e Vermeer: imanência na filosofia e na pintura, de Sara Hornäk, publicado no Brasil, em 2010, pela editora Paulus.

Palavras-chave: arte, imanência, imaginação, eternidade.

Sobre arte, Espinosa nos fala muito pouco. O termo, com o sentido estético que costumamos lhe atribuir, ocorre poucas vezes em toda a sua obra. Não é por acaso. No século XVII arte ainda conserva o sentido de um ofício específico, embora, como se sabe, o conceito de já arte estivesse em transformação desde o Renascimento, quando então ela tornou-se definitivamente inseparável das noções de beleza, estilo e originalidade, caminhando cada vez mais, sobretudo a partir do século XVIII, em direção ao sentido estético contemporâneo que hoje conhecemos. A arte no tempo de Espinosa não está longe, portanto, dos valores da contemplação e dos prazeres estéticos, mas é certamente menos importante a presença seja do artista ou do expectador que se situam num campo artístico sem pretender avançar para além de seus limites propriamente estéticos. Espinosa, por exemplo, situa as ciências e as artes no rol de todas as atividades humanas (e coletivas) que são necessárias ao aperfeiçoamento da "natureza humana" e à conquista da "beatitude". A arte não se separa, para ele, de sua utilidade

* Professor de filosofia do Curso de Servigo Social da Universidade Federal de São Paulo (Unifesp). 
ética, sem a qual ela talvez nem faça sentido. É o que parece nos indicar esta passagem do Tratado teológico-político:

[...] ninguém teria a força e o tempo necessário se fosse obrigado a lavrar, semear, ceifar, cozer, tecer, costurar e fazer sozinho tudo o mais que é preciso para o sustento, não falando já nas artes e ciências, que são também sumamente necessárias à perfeição da natureza humana e à sua beatitude (Espinosa 2, p. 85, grifos nossos).

Fazer arte não é o mesmo que tecer e cozer, certamente, mas deve servir, em última análise, aos mesmos propósitos éticos. Se é assim, a arte, enquanto tal, não poderia servir à própria tarefa de compreensão filosófica do mundo, de si e da Natureza? De fato, sabemos que quando Espinosa fala em "perfeição da natureza humana" e "beatitude" devemos entender o exercício de uma mente humana na compreensão de si, da essência singular de seu corpo, das coisas singulares e da Natureza inteira, da qual mente e corpo são expressões modais imanentes; e se a arte pode ser útil nessa tarefa, é porque deve conservar algum poder de compreensão. Haveria, assim, entre arte e filosofia, uma ligação talvez mais íntima do que alguns comentadores ou leitores de Espinosa gostariam de ver - justamente aqueles leitores ou cometadores para os quais a arte, pertencendo ao campo do primeiro gênero de conhecimento, a imaginatio, não teria nenhuma importância na obra do filósofo holandês, não podendo sequer poderia ser tomada como via de compreensão de sua filosofia.

Não é este o caso, felizmente, de Sara Hornäk, autora de Espinosa e Vermeer: imanência na filosofia e na pintura, livro publicado na Alemanha em 2004 e que chegou até nós no final de 2010 pela editora Paulus. Tratase de uma obra em que a arte é iluminada pela filosofia e a filosofia, pela arte; uma obra na qual vemos que um artista pode ser também filósofo, e um filósofo, artista. É que - Hornäk não hesitaria em afirmar - artista e filósofo habitam um mesmo mundo, um mesmo Universo, no sentido metafísico da palavra, de tal maneira que compartilham um mesmo "plano de imanência", para utilizar, em sentido menos sério, a expressão deleuziana. A relação que Hornäk estabelece entre Espinosa e Vermeer (consequentemente, entre filosofia e arte), é de tal ordem que a noção de imanência ganha um destaque e uma relevância que escapam muitas vezes até mesmo aos leitores de Espinosa. A imanência, como sugere o título da obra, é o elemento pelo qual a autora constrói sua argumentação que une a arte de Vermeer à filosofia de Espinosa; mas é também o alvo do livro, cujo objetivo principal parece ser o de mostrar que uma experiência estética da imanência realizaria por outros meios o mesmo que uma filosofia da imanência proporcionaria por meio do trabalho do pensamento.

Para chegar a esse resultado, contudo, a autora seguiu um caminho um tanto longo, mas muito acertado e talvez quase inevitável. Ela primeiro expôs toda a filosofia de Espinosa contida na Ética. Essa exposição, que ocupa a primeira parte do livro, tem antes de tudo o mérito de oferecer ao leitor um verdadeiro trabalho de introdução ao pensamento de Espinosa. Aí estão presentes os principais conceitos espinosanos. Substância, atributos, modos, conatus, afetos, afecções, liberdade e eternidade, entre outros, são apresentados ao leitor com o cuidado de quem deseja introduzi-lo no universo dessa difícil filosofia da imanência.

Nesta primeira parte, que ocupa mais da metade do livro, o pensamento de Espinosa é apresentado com certa fidelidade e clareza. Há contudo um momento de sua exposição em que a autora parece trair tanto o "espírito" quanto a "letra" do texto espinosano. Ela traduz amor Dei intellectualis por "amor espiritual a Deus" (Hornäk 3, p. 246). E devemos frisar que não há erro na tradução para o português, realizada por Saulo Krieger e revisada por Rachel Gazolla: no original alemão, a expressão 
da autora é die geistige Liebe zu Gott ("amor espiritual a Deus", grifo nosso). Trata-se sem dúvida de uma opção por "espiritual”, uma vez que uma das edições alemãs da Ética consultadas por Hornäk (elencadas no "Índice Bilbiográfico") é justamente a Ethik de W. Bartschat, que traduziu corretamente o amor Dei intellectualis por Die intellektuelle Liebe zu Gott. Caberia, então, uma nota de rodapé da autora explicando tal opção, assim como seria útil ao leitor brasileiro uma nota explicativa por parte do tradutor ou da revisora. É que não estamos aqui diante de uma questão menor: "amor espiritual a Deus" é uma tradução inaceitável para todos aqueles que sabem o quanto o "amor intelecutal de Deus" de Espinosa está longe de receber o sentido espiritualista do "amor a Deus" das tradições religiosas e teológicas judaico-cristãs. Ademais, tal opção seria menos problemática, não fosse o fato de estarmos, aí, num momento conclusivo do percurso filosófico realizado por Espinosa e que Hornäk reproduz em seu livro: precisamente no ponto de chegada do caminho filosófico espinosano, no ápice da tarefa da Ética, o leitor desprevinido pode ser levado a confundir Espinosa justamente com aqueles aos quais ele se contrapôs ética e filosoficamente. Afora esse deslize - que pode ser pequeno ou grande, a depender de se o leitor de Hornäk é ou não também um leitor de Espinosa - não há problemas na exposição da autora, embora tampouco haja aí novidades interpretativas.

Realizando esse longo percurso pelo pensamento espinosano, na primeira parte do livro, a autora pôde se desincumbir, na terceira parte, de explicar cada conceito espinosano, ao tratar da relação entre a arte de Vermeer e a filosofia de Espinosa. Mas antes de chegar a ela, a autora também nos oferece uma segunda parte, espécie de intermezzo histórico no qual o leitor se vê às voltas com os problemas da imanência e da transcendência, num percurso que vai de Platão a Giordano Bruno, passando pelos neoplatônicos e Nicolau de Cusa, sem deixar de nos oferecer ainda, ao final, algumas considerações sobre o "plano de imanência” de Gilles Deleuze. Mas é sem dúvida a terceira parte do livro que concentra o que ele tem de melhor. Aí encontramos as teses principais da autora; aí vemos a filosofia juntar-se à crítica e à história da arte para se chegar a bons resultados, seja no que concerne à compreensão do pensamento espinosano, seja no que toca à interpretação das obras de Vermeer.

A ideia central de Sara Hornäk é que a imanência pode ser não apenas pensada, mas também mostrada. A imanência, para além de sua expressão recebida no trabalho de pensamento filosófico, se exprimiria também em outros campos do fazer humano - na arte, por exemplo, e Vermeer seria aqui exemplo privilegiado, particularmente $A$ leiteira, obra sobre a qual se centram as interpretações da autora.

$\mathrm{Na}$ forma, na tecedura e combinação das cores, assim como no uso da luz, Vermeer deixaria ver ou daria visibilidade à mesma imanência de que nos fala Espinosa. Hornäk vê no tratamento de temas cotidianos precisamente uma recusa da transcendência em Vermeer. Não se trata de que nas obras do pintor encontraríamos a representação da imanência: dáse antes que a própria imanência estaria aí presente, visível, expressa na tela mesma. Em Vermeer, assim como na teoria da mente da Ética, não haveria então a representação de ideias, motivos ou objetos; a própria imagem produziria seu sentido, assim como um sentido emerge no próprio texto da Ética - e Hornäk fala aqui em "autorreferencialidade", em "estrutura de expressão horizontal", para dar conta dessa potência expressiva imanente ao texto e à imagem (Hornäk 3, p. 329).

Arte e filosofia, entretanto, conservam esta potência expressiva de maneiras diferentes, cada uma a seu modo, em seu próprio campo e com seus próprios recursos. Hornäk não sonha estabelecer qualquer relação causal entre Vermeer e Espinosa. Ao mesmo tempo, ela vê no "conhecimento da imanência, que, segundo Espinosa, se dá intuitivamente” (Hornäk 3, p. 331), 
o elemento comum que os une. A intuição, que a autora corretamente vê, não como uma superação mística do racionalismo, mas como uma ampliação da própria razão, seria assim o meio pelo qual a imanência é inteligida e vivida, tanto em Espinosa quanto em Vermeer. Essa experiência intelectual e afetiva da imanência, que Espinosa exprime no conceito de amor intelectual de Deus, em Vermeer estaria presente na "quietude profunda" que Hornäk vê "expressa" em seus quadros, os quais permitiria uma certa "contemplação da eternidade"... (Hornäk 3, p. 331-333).

Mas de que forma, do ponto de vista da filosofia de Espinosa, tudo isso seria possível? A arte não é de fato uma atividade que se dá antes de tudo no campo da imaginação e portanto da ideia inadequada? Contudo, segundo Hornäk devemos superar a ideia de imaginatio como mero conhecimento inadequado. Lembremos que a imaginação, enquanto tal, está inscrita no rol das atividades dos modos finitos, o que significa que ela mesma é algo, é modo e constitui um modo de ser. Sabemos, ao mesmo tempo, onde está o problema teórico e prático da imaginatio: caímos no inadequado ao afirmarmos de um conteúdo imaginativo que ele é verdadeiro ou falso, bom ou mau, quando o próprio conteúdo não nos oferece tanto. Como estamos sempre no exercício do nosso conatus, é quase inevitável que a imaginação não venha acompanhada dessas afirmações ou negações. No entanto, o próprio conatus pode exercer-se de tal forma que a imaginação não seja um obstáculo, mas um reforço.

A imaginação, muitas vezes, é antes uma potência, em vez de impotência e passividade. Flaubert e Machado de Assis nos dão a ver certas paixões humanas. Mas no ato mesmo em que escrevem, não são dominados por elas. A imaginação no artista é, em casos como esses, um potente instrumento de criação, não de dominação daquele que imagina. Hornäk nos lembra que, na abertura do Breve Tratado, a forma de exposição é já artística; ademais, a própria forma de exposição geométrica da Ética é, para a autora, igualmente artística, pois faria emergir uma "estrutura complexa" em que definições, axiomas, proposições e demonstrações se mostrariam de tal forma interligados que, ao fim do texto, seríamos capazes de vê-lo todo, seríamos capazes de ver a simultaneidade da forma, assim como seríamos capazes de apreender a nossa essência singular inseparavelmente do Universo (o todo), da mesma maneira que a autorreferencialidade presente nos quadros de Vermeer nos dariam a ver o próprio real em sua simultaneidade.

Hornäk vê nos quadros de Vermeer a expressão do que ela chama de "força substancial" em meio às próprias coisas cotidianas. Os elementos cotidianos do pintor realizam a imanência pictoricamente. A arte pode tornar a imanência visível. Em Vermeer, mais do que em qualquer outro pintor do XVII, segundo Hornäk, dá-se justamente essa visibilidade da imanência. Para a autora, a imanência não é uma ideia puramente conceitual, e portanto não se trata de buscar na arte o sentido da imanência, mas sim de entender como ela se exprime na arte.

Vermeer retrata o cotidiano de tal forma que o que se exprime na tela é o singular (não o geral, isto é, não uma casa, um quarto, um vaso ou uma mulher, mas esta casa, este quarto, este vaso, esta mulher). Tomando sempre como referência A leiteira, Hornäk considera que o humano e o mundo estão igualmente presentes na tela de Vermeer, através da figuração plástica de uma mulher, um lugar e uma ação singulares. A singularidade do gesto da leiteira exprime-se em sua total concentração na realização do ato cotidiano de despejar o leite que sai de uma recipiente e entra em outro. Concentração e movimento, aqui, encerram a "quietude" que se exprime no gesto da leiteira. Para Hornäk, a apreensão intuitiva do "verter do leite" equivale a uma experiência da eternidade, uma vez que a Natureza se exprime nos modos e portanto também nos gestos mais cotidianos. 
Para chegar a essas conclusões, Hornäk analisa o uso das cores, da luz e do que ela chama de "superfície de imagem e espaço de imagem", em Vermeer. $O$ trabalho de composição e combinação das cores mostra o quanto elas formam uma trama, uma tessitura, pela qual Vermeer "escreve" o "texto" da tela, de tal maneira que a imanência se faria presente no próprio ato criativo do pintor. Para Hornäk, entretanto, sem o uso específico que Vermeer faz da luz essa trama das cores seria impossível. Aqui, como muitos historiadores lembraram, o procedimento estético é o chiaroscuro. Hornäk lembra, porém, que o uso desse procedimento é de tal ordem que o chiaro não se opõe ao oscuro. Claro e escuro não são oposições irredutíveis. Em vez disso, eles formariam uma "unidade harmônica". O homem não se opõe ao mundo; é dele um elemento discernível mas inseparável, componente intrínseco do todo. Mas de onde vem a luz, em A leiteira? Segundo Hornäk, a luz intensa da parede não pode advir dos vidros da janela à esquerda da tela, porque eles estão demasiados embaçados para produzir uma tal luminosidade ${ }^{1}$. A luz da parede, intensa e profunda, seria produzida ali mesma, por ela mesma: ela seria, assim, figuração pictórica da causa imanens, da causa que não se separa do efeito após causá-lo. Certamente a importância que a autora dá ao papel da luz não é casual. Ela mesma nos lembra que para uma longa tradição de religiosos e pensadores a luz sempre foi considerada "símbolo do divino". Mas a luz, em Vermeer, não seria o que remete a outra coisa, a algo fora da tela, ao transcendente: ela se dá e se constitui no cotidiano mesmo, alia onde as coisas estão, em meio a elas e por meio delas.

É contudo no momento em que analisa o problema da superfície e do espaço da imagem que a interpretação de Hornäk fica ao mesmo tempo mais interessante e mais controversa. Mais interessante porque aprofunda a interpretação da obra de Vermeer pela ótica da imanência espinosana; mais controversa porque, nesse aprofundamento, parece realizar uma leitura “piedosa", "espiritualista" e um tanto mística da filosofia de Espinosa. E, realmente, a partir da análise de elementos formais de A leiteira, Hornäk identifica a figuração pictórica de temas como a "concentração" e a "quietude". A mulher que no centro da tela faz jorrar o leite na vasilha sobre a mesa realiza esse ato com toda a atenção, compenetrada em seu gesto, a ponto de ela, sua ação, os objetos que a cercam, o próprio lugar, enfim, comporem uma "cena hermética" que exprime "concentração" plena e, por isso mesmo, certa "quietude".

Nesta "cena hermética" encontra-se, porém, a abertura para todo o Universo, afirma Hornäk. A autora fala no "mundo sumamente próprio" e na "interiorização absoluta" que as telas de Vermeer deixariam ver. E, no entanto, precisamente aí encontraríamos "o atrelamento, tão difícil de apreender, entre finitude e infinitude" (Hornäk 3, p. 378). Haveria, então, uma espécie de "filosofia da imanência", não dita, não escrita, mas figurada nas telas de Vermeer, particularmente em A leiteira? As análises e interpretações de Hornäk parecem querer levar o leitor a essa conclusão. E de fato uma tal conclusão em Vermeer seria tanto mais possível quanto, segundo Hornäk, "o pintor suprime dualismos em teoria do conhecimento, como o que se tem entre imaginatio e ratio, corpo e alma, percepção e conhecimento" (Hornäk 3, idem).

Não é que autora desconheça o lugar da imaginatio na Ética de Espinosa. Sabe que na imaginação estamos sempre às voltas com o inadequado. Mas ela lembra que a conquista do adequado, em Espinosa, não se faz pela defesa "de um ponto de vista puramente racionalista", já que Espinosa vai além da razão sem dispensá-la: a ciência intuitiva, o terceiro gênero de conhecimento, faz de Espinosa um racionalista sui generis no século XVII, pois com ela a própria razão se vê ampliada - não porque seja agora capaz de apreender mais generalidades, mas, ao contrário, porque capaz de captar singularidades, antes de tudo da essência singular 
do corpo de que esta mente intuitiva é a ideia. Contudo, precisamente a ciência intuitiva dá à imaginatio um outro estatuto: à imaginação não é mais dado o valor de verdade que era fonte de todo o erro (lembremos que a imaginação em si não é nem falsa nem verdadeira), mas antes um lugar na contemplação adequada de si que envolve uma outra imagem de si mesmo, das coisas e da Natureza (ou Deus), assim como da ligação necessária (eternidade) entre nós, as coisas e a Natureza.

A ciência intituitiva, portanto, envolve razão e imaginação, mas agora sob o aspecto da eternidade. Ora, precisamente esse conhecimento intuitivo corresponde, na arte, segundo Hornäk, à "uma atitude contemplativa, na qual o homem, mergulhado em si mesmo, assume um estado de interiorização". Essa "interiorização" intuitiva estaria presente em A leiteira: "A criada parece espreitar a si mesma" (Hornäk 3, p. 382). Evidentemente, não estamos aqui diante de uma interiorização que nos faria cair num sopsismo sem saída de si, precisamente porque, realizandose no campo da ciência intuitiva, ela é por isso a expressão da ligação que mente tem com a Natureza inteira, e, portanto, em vez de nos fechar em nós mesmos, ela é capaz de nos abrir a todas as coisas, ou, o que é o mesmo, de realizar uma abertura ao "múltiplo simultâneo", para utilizar uma expressão de Marilena Chaui (Chaui 1, p. 103). É aqui que, para Hornäk, somos capazes de apreender o eterno no temporal, o infinito no finito, a Substância nos modos.

O que, entretanto, em A leiteira de Vermeer, revela-nos esse poder de apreensão intuitiva do real e de nós mesmo na Natureza? Aqui aparece com mais clareza aquele ponto controverso a que nos referimos acima. Para Hornäk, pode-se ver na ação da criada, em sua expressão, em seu gesto, uma atitude de "concentração", "paciência" e "quietude". E a autora chega mesmo a falar em "humildade", dando-lhe outro sentido, que não é o de Espinosa: se para este a humildade é contemplação da própria impotência, para a autora ela é "dedicação plena de devoção", que o gesto da criada deixaria entrever. Se, agora, reunirmos estes termos e expressões àquele "amor espiritual a Deus", não poderíamos ver aí uma interpretação um tanto "piedosa", isto é, religiosa, e espiritualista da filosofia de Espinosa, mas também das obras de Vermeer? Mas deixamos ao leitor um julgamento mais apurado e justo do livro. Em todo caso, é verdade que, por outro lado, o texto de Hornäk deixa entrever que humildade, paciência, quietude e concentração querem exprimir apenas um estado de alegria ativa, em que se fundem atividade e passividade, ação e contemplação, obra e expectador, texto e leitor. Para Hornäk, Vermeer desfaz de tal forma a oposição entre interioridade e exterioridade, que o observador pode tomar parte na atitude contemplativa da personagem figurada na tela.

Mas a conclusão talvez mais importante de Hornäk, nesse momento de seu percurso interpretativo, é a de que as figuras retratadas nos quadros de Vermeer não narram acontecimentos, mas exprimem a eternidade. Na concentração tem-se o elemento da atenção - e Hornäk não deixa de lembrar pelo menos um intérprete de Vermeer que tenha destacado o fato de que na arte holandesa do XVII ocorreu a representação do mais alto grau de atenção envolvido na atividade doméstica (Hornäk 3, p. 384). Concentração, atenção, presente. Para os zen-budistas, a beatitude não se faz fora do tempo presente, esse tempo que é o mais difícil de ser vivido, como dizia Jorge Luis Borges. E se não narra acontecimentos, nem por isso Vermeer figura naturezas mortas congeladas no tempo (como se tal fosse possível). Em vez disso, o pintor "dilata o passo temporalmente mensurado para uma duração que nos possibilita a eternidade" (Hornäk 3, p. 394), escreve Hornäk. E então compreendemos que o leite jorrado da leiteira "flui eternamente" (Hornäk 3, p. 396). O leite sendo derramado é um "transcurso", é duração eterna ou um "demorado agora" no todo da eternidade. 
Muitos intérpretes falaram do "enigma" na obra de Vermeer. Para Hornäk este enigma consiste em tornar visível o que é da ordem do invisível: a eternidade e a imanência. Mas não é isso o que precisamente Espinosa nos faz ver, sobretudo com sua Ética? A diferença é que enquanto aí os "olhos da alma" são as demonstrações geométricas da mente, em Vermeer os "olhos da mente" são os próprios olhos do corpo diante da visibilidade de uma obra que mostra a imanência e eternidade dos gestos, das coisas, do homem. Hornäk não hesita em afirmar que "na obra de Vermeer se realiza a imanência”. E poderia ser diferente? Não seria correto dizer que, se todos os modos são modificações da Substância única que lhes é imanente, como eles a ela, a própria Substância está de algum modo em todas as coisas, em todos os gestos, em todos os homens, em todas as obras? Correto, mas, precisamente, ela se faz presente de maneiras diferentes. Há maneiras e maneiras de exprimir o Ser. Podemos fazê-los mais ou menos. Às vezes se está mais próximo de si mesmo; às vezes se está tão longe de si que é então a quase pura passividade o que impera. Neste último caso, um gesto, uma obra, uma ação exprimem apenas a exterioridade das relações e já não dizem quase nada, ou fazem muito pouco pela perfeição de nossa natureza e por nossa beatiude.

Sara Hornäk relembra uma passagem de O Olho e o espírito, na qual Merleau-Ponty afirma que na obra de Cézanne se "produz um cintilar do ser [...] em todos os modos do espaço e também na forma" (Hornäk 3, p. 415-416). O mesmo, segundo Hornäk, se passa em Vermeer. Há nele a criação de uma "outra" realidade, sua obra remete a um "para além" do que se vê e se sente, mas ele o faz justamente no que se vê e se sente. "A segurança e capacidade com que a figura representada", escreve Hornäk ainda sobre $A$ leiteira, "realiza sua atividade permite que a cena apareça à luz da necessidade”. Eis, em Vermeer, a potência intrínseca da própria obra, a figuração do instante que se inscreve numa ontologia do necessário e que por isso mesmo torna visível a eternidade e imanência dos gestos, dos modos, dos acontecimentos. E, assim, por caminhos diferentes encontraríamos, em Vermeer como em Espinosa, uma mesma unidade de ser e agir, uma mesma afirmação da vida no presente, uma mesma potência de agir que se inscreve no seio da atividade eterna (sempre presente) dos atributos divinos que constituem a essência da Substância absolutamente infinita.

$$
* * *
$$

Deleuze amava dizer que a alegria espinosana realiza-se no mesmo ato de um bom encontro. Não se sabe se algum dia Espinosa encontrou-se com Vermeer, apesar de terem morado próximos um do outro, pelo menos durante os 17 anos em que Espinosa, mesmo tendo habitado diferentes cidades, não se afastou muito de Delft, a cidade de Vermeer. Mas Hornäk consegue realizar agora, para nós, esse bom encontro entre o filósofo e o pintor, entre a filosofia e arte, percorrendo o mesmo fio imanente que une um e outro, uma e outra, e todos nós.

\section{REVIEW: ART AND IMMANENCE: A GOOD ENCOUNTER BETWEEN SPINOZA AND VERMEER}

Abstract: Review of the book Vermeer and Spinoza: Immanence in philosophy and painting, Sarah Hornak, published in Brazil in 2010 by publisher Paulus.

Keywords: art, immanence, imagination, eternity. 


\section{REFERÊNCIAS BIBLIOGRÁFICAS:}

1. CHAUI, Marilena de S. "Ser Parte e Ter Parte: Servidão e Liberdade na Ética IV". In: Discurso, no. 22, 1993

2. ESPINOSA, Baruch de. Tratado teológico-político. São Paulo: Martins Fontes, 2003.

3. HORNÄK, Sara. Espinosa e Vermeer: imanência da filosofia e na píntura. São Paulo: Paulus, 2010.

NOTAS:

1. Há um pequeno buraco, num dos vidros, que deixa ver o quanto eles estão embaçados, provavelmente pelo calor do ambiente interno em oposição ao frio do exterior.

\section{RESENHA: A UNIDADE DO CORPO E DA MENTE: AFETOS, AÇÕES E PAIXÕES EM ESPINOSA}

Bruno D’Ambros**

Resumo: Resenha do livro A unidade do corpo e da mente: afetos, ações e paixões em Espinosa, de Chantal Jaquet, publicado no Brasil em 2011 pela editora Autêntica Palavras-chave: Espinosa, unidade, monismo, afetos.

Lançado na França em 2004, o livro de Chantal Jaquet chega ao Brasil em 2011, publicado pela editora Autêntica. A tese da união entre mente e corpo de Espinosa tem despertado o interesse de neurobiologistas e psicomotricistas pelo filósofo holandês. Porém, como toda popularização implica quase sempre numa simplificação, surge o receio de que possa haver tal simplificação de Espinosa. É neste intuito que surge o livro de Chantal Jaquet, como precaução de eventuais abusos e simplificações extremas da filosofia de Espinosa e também como um estudo aprofundado das relações entre a mente e o corpo "sob o prisma dos afetos." (JAQUET 1, p.17)

O livro se divide em cinco capítulos, cujos títulos são: "A natureza da união do corpo e da mente", "A ruptura de Espinosa com Descartes a respeito dos afetos na Ética III”, "A gênese diferencial dos afetos no prefácio do Tratado teológico-político e na Ética", "A definição do afeto na Ética III”, "As variações do discurso misto."

* Graduando em Ciências Sociais pela Universidade Federal de Santa Catarina 